\title{
Vibration Monitoring of a Steel-Plated Stress-Ribbon Footbridge: Uncertainties in the Modal Estimation
}

\author{
José M. Soria ${ }^{1}$; Iván M. Díaz²; Jaime H. García-Palacios³; and Norberto Ibán ${ }^{4}$
}

\begin{abstract}
A low-cost vibration-monitoring system was developed and installed on an urban steel-plated stress-ribbon footbridge. The system continuously measures the acceleration [using 18 triaxial microelectromechanical system (MEMS) accelerometers distributed along the structure), the ambient temperature, and the wind velocity and direction. Automated output-only modal parameter estimation based on the stochastic subspace identification (SSI) was carried out to extract the modal parameters (i.e., the natural frequencies, damping ratios, and modal shapes). Thus, this study analyzed the time evolution of the modal parameters over data monitoring for 1 year. First, for similar environmental/ operational factors, the uncertainties associated with the SSI-based techniques used and to the acceleration records used were studied and quantified. Second, a methodology for tracking the vibration modes was established, because several of them with closely spaced natural frequencies were identified. Third, the modal parameters were correlated against external factors. It has been shown that this stress-ribbon structure is highly sensitive to temperature variations (frequency changes of more than 20\%) with strongly seasonal and daily trends. Fairly simple dynamic multiple regression models for the lowest persistent vibration modes were derived, and excellent correlations for some of them were obtained. These correlations enable the influence of these uncertainties on modal estimates to be removed, thus facilitating their use as damage-sensitive features. DOI: 10.1061/(ASCE)BE.1943-5592.0000830. () 2016 American Society of Civil Engineers.
\end{abstract}

Author keywords: Footbridges; Continuous dynamic monitoring; Environmental effects; Operational modal analysis.

\section{Introduction}

The long-term vibration monitoring of civil engineering structures is increasingly used to monitor both structure integrity and vibration serviceability. A number of examples of bridges and footbridges equipped with a monitoring system can be found (Cross et al. 2013; Gomez et al. 2011; Moser and Moaveni 2013; $\mathrm{Hu}$ et al. 2012). In these monitoring systems, the vibrations due to traffic or wind are measured and recorded. These data can be used to continuously extract the modal parameters (natural frequencies, damping ratios, and modal shapes), which may be used to assess structural integrity, because structural damages lead to changes in the modal parameters. Thus, vibration-based structural health monitoring (SHM) systems using automated output-only modal identification [also known as operational modal analysis (OMA)] have been extensively proposed (e.g., Deraemaeker et al. 2008; Magalhães et al. 2012). One of the main problems of these systems is that they have to cope with changing environmental/operational conditions that

${ }^{1}$ Ph.D. Candidate, E.T.S de Ingenieros de Caminos, Univ. Politécnica de Madrid, c/Prof. Aranguren s/n, 28040 Madrid, Spain. E-mail: jm .soria@upm.es

${ }^{2}$ Associate Professor, E.T.S de Ingenieros de Caminos, Univ. Politécnica de Madrid, c/Prof. Aranguren s/n, 28040 Madrid, Spain (corresponding author). E-mail: ivan.munoz@upm.es

${ }^{3}$ Associate Professor, E.T.S de Ingenieros de Caminos, Univ. Politécnica de Madrid, c/Prof. Aranguren s/n, 28040 Madrid, Spain. E-mail: jaime.garcia.palacios@upm.es

${ }^{4}$ Ph.D. Candidate, Cartif Research Center, Boecillo, 47011 Valladolid, Spain. E-mail: noriba@cartif.es

Note. This manuscript was submitted on December 1, 2014; approved on July 14, 2015; published online on January 4, 2016. Discussion period open until June 4, 2016; separate discussions must be submitted for individual papers. This paper is part of the Journal of Bridge Engineering, (C) ASCE, ISSN 1084-0702. often significantly affect the modal estimation. Hence, the removal of these spurious factors on modal estimates becomes crucial in the implementation of a SHM system, which uses modal parameters as damage-sensitive features. These factors may mask meaningful changes for damage detection due to, for instance, extraordinary events such as earthquakes or very dense traffic (Stiros and Moschas 2014), especially in structures, such as bridges, that are always exposed to environmental factors.

The main obstacle for a more widespread adoption of these monitoring systems is the cost associated with their installation. Recently, a successful attempt to reduce the cost of a monitoring system was carried out through the use of low-cost sensors to measure structural vibrations on a footbridge. Thus, a low-cost continuous vibration-monitoring system using small microelectromechanical system (MEMS) accelerometers was developed and installed on Pedro Gómez Bosque (PGB) footbridge (Valladolid, Spain) to track its long-term dynamic performance. The system continuously measures the acceleration (using 18 triaxial MEMS accelerometers distributed along the structure), the ambient temperature, and the wind velocity and direction (de Sebastián et al. 2013). PGB footbridge is a singular steel-plated stress-ribbon footbridge with a single span of $85 \mathrm{~m}$. The dynamic behavior shows several low-frequency vibration modes with closely spaced natural frequencies and low damping ratios.

A procedure for tracking vibration modes was programmed to carry out an automatic modal parameter estimation. This procedure has to cope with vibration modes with closely spaced natural frequencies. In this case, sorting vibration modes using frequency criteria and removing outliers that lay out of intervals of frequency variation might not be adequate (Magalhães et al. 2008a; Moser and Moaveni 2013). This paper describes the detailed procedure carried out to track vibration modes of PGB footbridge over time. The procedure uses three tolerances based on the modal assurance criterion (MAC). This approach enables reliable monitoring of vibration modes that are maintained over time. 
Regarding the use of modal parameter variations as a possible damage detector in structures, it is necessary to observe the modal variations over time that result from the influence of some external agents acting on the undamaged structure (Magalhães et al. 2008a; Koo et al. 2013). It is important to evaluate the magnitude of this modal variation and the main factors that influence the relationship between them. The temperature is usually the most significant environmental factor (Zhou et al. 2011). However, other factors, such as operational or boundary conditions, may significantly affect the modal estimates (Avci 2014; Koo et al. 2013). Several studies have dealt with this problem and included correlation analyses between modal estimates and these external factors (Ni et al. 2005; Liu and DeWolf 2007; Hua et al. 2007; Mosavi et al. 2012; López and Astiz 2014).

Finite-element models are usually updated by using the modal parameters (Cismaşiu et al. 2014; Moaveni and Behmanesh 2012). However, when the modal parameters show significant variability with changing environmental factors, the updated model might not be as accurate as required (Bayraktar et al. 2009). Hence, it is important to estimate uncertainties in the modal parameter identification to establish the degree of confidence of the updated model. This updated model can be useful for guaranteeing a successful structural intervention during structural rehabilitation (Costa et al. 2014; Ivorra et al. 2013). That is, nondestructive tests, such as an OMA, together with calibrated models greatly benefit reliable structural evaluations.

The methods available for performing the identification of modal parameters of dynamic systems based on OMA are usually classified as frequency domain or time domain methods, which have been extensively studied in the literature (MacLamore et al. 1971; Overschee and Moor 1996; Andersen 1997; Jacobsen et al. 2008; Zhang et al. 2010). Formulations that use state-space models, designated as stochastic subspace identification (SSI) methods, constitute the parametric approach that is adopted more commonly for civil engineering applications in the time domain. They are also recommended when there are closely spaced eigenfrequencies (Magalhães et al. 2008b; Magalhães and Cunha 2011). Accordingly, the methods discussed in this paper are based on the SSI techniques.

The paper continues with the description of the structure and its monitoring system. The uncertainties associated with a single timehistory record are discussed in Peered Analysis of One Test. The output-only modal parameter estimation using three SSI-based OMA techniques and different data blocks was carried out. Thus, uncertainties that result from the selection of the SSI technique and the data block were quantified. The results of continuous dynamic analysis are described in the Continuous Dynamic Analysis section. A tracking method for following the evolution of the persistent vibration modes over time is proposed. The influence of the environmental/operational factors on the modal estimates was studied, and correlation models were derived to remove the influence of these spurious factors. Finally, some conclusions are drawn, and suggestions for future work are given.

\section{The Footbridge and Its Vibration Monitoring}

\section{Structure Description}

The PGB footbridge, sited in Valladolid, is a slender and lightweight structure that creates a pedestrian link over the Pisuerga River between a sport complex and the city center (see Fig. 1). This bridge, built in 2011, is a singular stress-ribbon footbridge born by a pretensioned catenary-shaped steel band with a single span of $85 \mathrm{~m}$

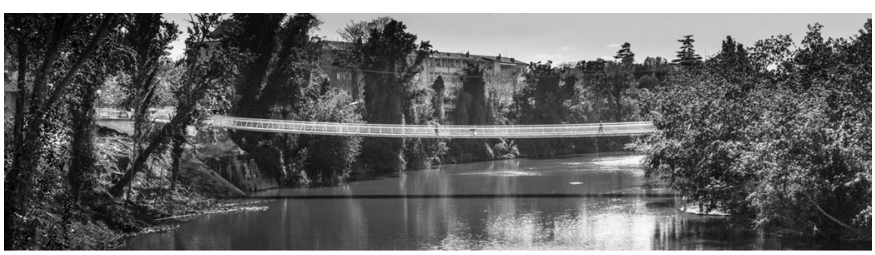

(a)

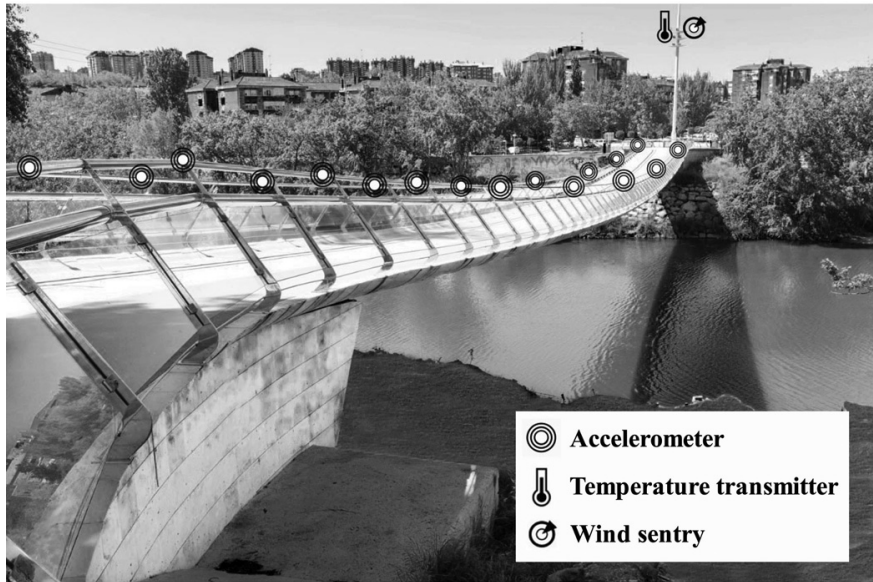

(b)

Fig. 1. PGB footbridge (images courtesy of J. Muñoz-Rojas): (a) landscape view; (b) distribution of sensors

that has a minimal impact on the surroundings. The structure mainly consists of a Corten steel band $94 \mathrm{~m}$ long, $3.6 \mathrm{~m}$ wide, and only 30 $\mathrm{mm}$ thick that is pretensioned and anchored to the two abutments. The complete steel band was fabricated by welding 8 -m-long sheets, and a number of 110 precast concrete slabs lay on the steel band (Narros 2011). These slabs do not have bearing capacity; the only structural element is the band. The structure was completed by rubber flooring and a stainless steel glass handrail.

\section{Monitoring System}

A structural vibration-monitoring system was devised to continuously estimate the modal parameters of the structure and to assess their changes under various environmental conditions. Therefore, along with the accelerometers, needed for performing modal analysis, sensors for wind and environmental temperature conditions were installed. The monitoring system comprises 18 triaxial accelerometers (nine at each side of the deck), a temperature sensor, and an anemometer with a vane. Wires and acceleration sensors were installed inside the handrail, so the structure aesthetic was not modified in any way, which introduced the following additional complications: (1) the installation process was laborious, and (2) additional angular transformations are required to obtain the acceleration vector in the structure axes for each accelerometer.

The vibration sensor used for the monitoring system was the low-cost MEMS accelerometer ADXL327 (Analog Devices, Norwood, MA), which measures the static acceleration of gravity. The ADXL327 is a very small, low-power, three-axis accelerometer with signal conditioning voltage output. The key properties of this sensor are that it has a measurement range of up to $\pm 2.5 \mathrm{~g}$, a sensitivity up to $500 \mathrm{mV} / \mathrm{g}$, and a bandwidth up to $550 \mathrm{~Hz}$. However, this sensor was not designed to transmit a signal over long distances. To overcome this problem, an ad-hoc conditioning circuit was designed to enhance its long-distance performance. First, three capacitors, one to each channel, were placed to fix the frequency 
bandwidth to $100 \mathrm{~Hz}$. Second, because the accelerometer has to be supplied by $3.6 \mathrm{~V}$ to get its maximum nominal sensitivity of 500 $\mathrm{mV} / \mathrm{g}$, the $12-\mathrm{V}$ power supply unit and a $3.6-\mathrm{V}$ voltage regulator were integrated into each circuit board to avoid power losses by the long-distance wires. Third, an operational amplifier was used to reduce significantly the output impedance, which enabled a good signal-to-noise ratio for the acceleration parameter (constant sensitivity and low noise). The achieved signal-to-noise ratio was $25 \mu \mathrm{g} / \sqrt{\mathrm{Hz}}$, which was considered to be enough for monitoring the structural vibrations. Finally, each circuit board with all its components was covered with a plastic coating to protect it from environmental conditions. Then, the accelerometers were ready to be installed inside the tube of the handrail. The sensing system was completed by a temperature sensor (Model T0110 transmitter, Comet, Rožnov pod Radhoštěm, Czech Republic) and a wind sentry (Model 03002L, R. M. Young Company, Traverse City, MI) to measure the speed and direction of the wind. The temperature sensor and wind sentry were installed on the public light tower sited closed to the structure [see Fig. 1(b)].

The monitoring system comprises 57 voltage channels that are processed continuously. The data logger CompactRIO 9076 (National Instruments, Austin, TX), with two NI 9205s with 32 analog input channels, is used for real-time data acquisition. The frequency sampling for each channel was chosen to be $200 \mathrm{~Hz}$, enough to identify the modal parameters of the structure and to avoid aliasing problems during postprocessing.

The actual orientation of the accelerometers installed inside the handrail is unknown. However, the Euler angles between the accelerometer coordinate system and the structure coordinate system can be derived while taking into account the following: (1) the longitudinal axis of each accelerometer matches with the longitudinal axis of the footbridge, and (2) the accelerometers can measure acceleration due to gravity. Therefore, the transformation matrix between both coordinate systems can be obtained, and then the acceleration in the global axes can be finally calculated (de Sebastián et al. 2013). Before its final installation, laboratory validation was carried, out and after the installation, an in situ validation was performed by comparing the data against those of conventional piezoelectric accelerometers.

\section{Peered Analysis of One Test}

The uncertainties associated with the modal identification of one test, corresponding to the record measured on January 5, 2013, at 19:16 (60-min test), are analyzed herein. The dynamic behavior of the structure is governed mainly by the vertical response (previous time-history analyses have shown that lateral and longitudinal accelerations are small and negligible, respectively, compared to those of vertical ones), which is why this analysis concentrates on the vertical vibration. The process is as follows. First, signal processing is undertaken before the modal identification is presented. Afterward, identification from the same test $(60 \mathrm{~min})$ is performed by using different OMA techniques. Then, the same technique is applied to different 20-min time windows of the 60-min test.

\section{Data Processing}

The vertical response of the structure in a 1-h test is analyzed (with an initial sampling frequency of $200 \mathrm{~Hz}$ ). The signal is filtered by a low-pass Butterworth filter of order 4 with a cutoff frequency of $5 \mathrm{~Hz}$. A decimation factor of 16 is applied, and a Nyquist frequency of $6.25 \mathrm{~Hz}$ is obtained. As an example, Figs. 2( $\mathrm{a}$ and b) show the filtered and decimated responses in time and frequency domain,
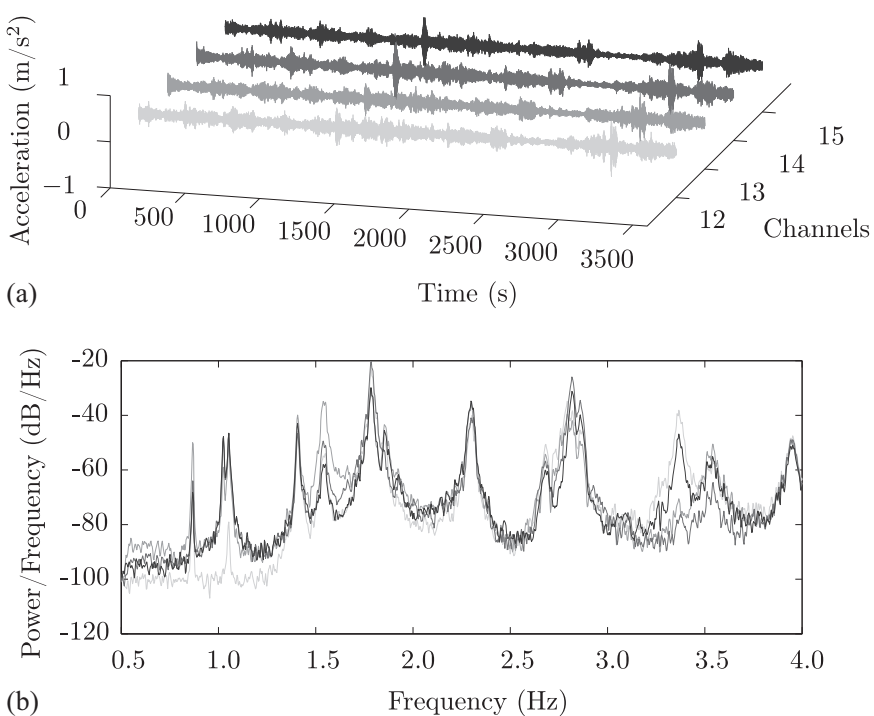

(b)

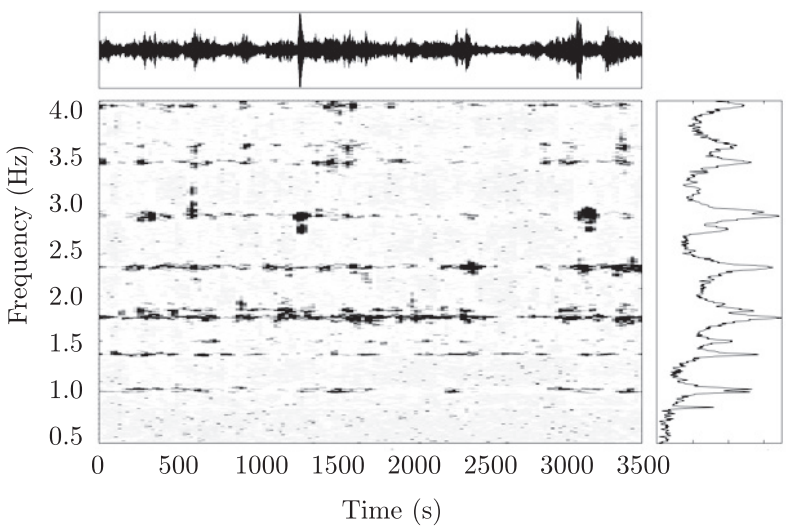

Fig. 2. Processed raw data of four central channels on the upstream side: (a) time domain; (b) frequency domain; (c) spectrogram of channel 15 using the short-time Fourier transform

respectively, corresponding to the four central channels for the upstream side. Fig. 2(c) shows the spectrogram using the short-time Fourier transform for channel 15; up to 10 horizontal alignments below $4 \mathrm{~Hz}$ can be seen.

\section{Operational Modal Analysis Using Three SSI Techniques}

Three different OMA techniques based on the SSI (Overschee and Moor 1996) and programmed in MATLAB 8.3.0.532 are used for the same test. The techniques used are covariance-driven SSI (SSIcov), data-driven SSI (SSI-data), and expectation maximization SSI (SSI-EM). The same criteria for defining a pole of the stabilization diagram as stable are used for the three identification techniques. To define a pole as stable, three requirements against estimates of the previous state-space order must be fulfilled: (1) the frequency must match within $1 \%$ (relative), (2) the damping ratio must match within 5\% (absolute), and (3) the mode shapes must match within $95 \%$, using the MAC for comparing. In addition, modes with identified damping ratios higher than $5 \%$ are also rejected.

The advantages of SSI-cov, programmed in MATLAB, are its conceptual simplicity and its ability to compute the probability density function of the identified system parameters. It selects the average 


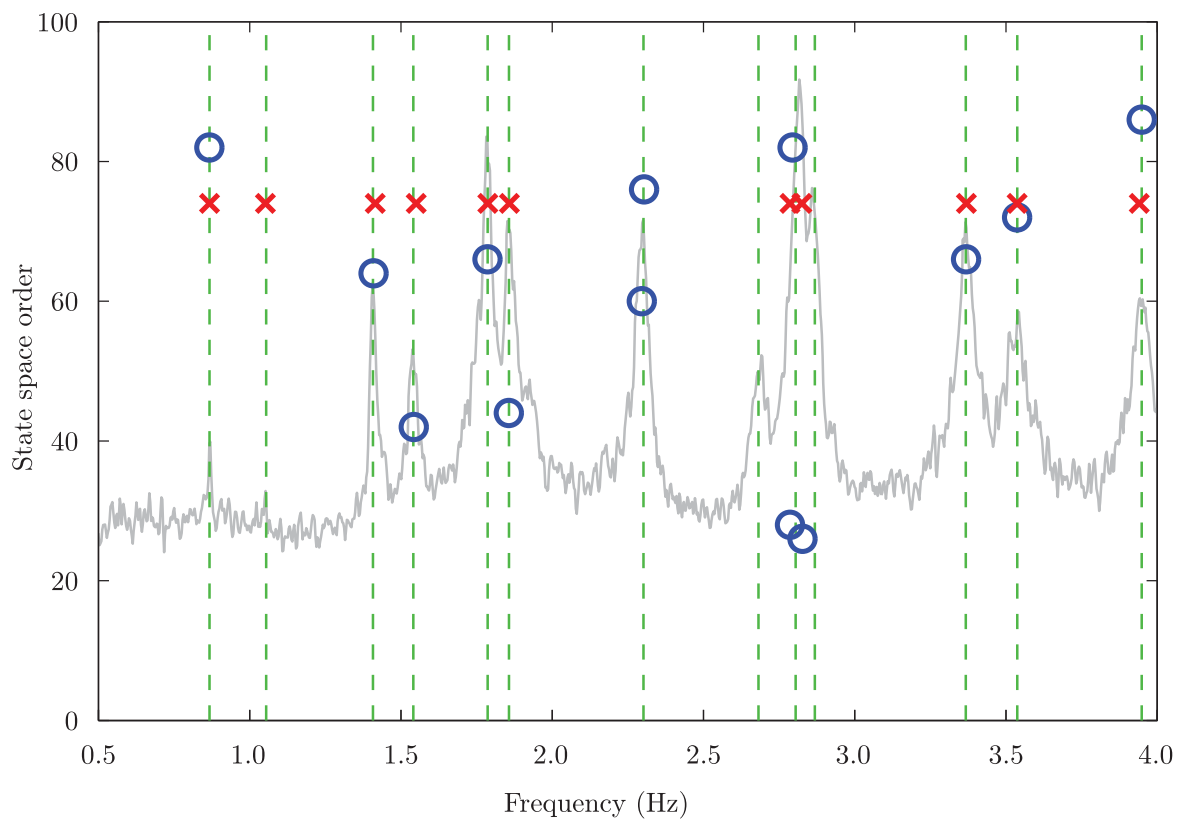

Fig. 3. Selected poles: SSI-cov (dashed lines), SSI-data (circles), and SSI-EM (crosses)

values of the modal parameters for each column (of stable aligned poles) with a minimum number of stable poles (Peeters and De Roeck 1999). SSI-data has been applied by using MACEC [Commercial Toolbox of MATLAB for modal analysis (Reynders et al. 2008)] and has the advantage of providing optimal statistical performance when the weighting matrices are chosen properly. A statistical analysis of the stable poles is used to choose final results (Reynders et al. 2012). SSI-EM is a combination of SSI and the EM algorithm. Using SSI for the initial estimate, the maximum-likelihood estimation requires iterations when using the EM algorithm (Cara et al. 2012). SSI-EM introduces the EM algorithm (McLachlan and Krishnan 2007) to maximize the likelihood function, which optimizes the lack of optimal solution shown by Bauer (2005) and Chiuso and Picci (2004) and improves the SSI results but does not define criteria for choosing the pole in the stabilization diagram. That is, the poles are those obtained by the modal order previously selected by an experienced user. Fig. 3 illustrates the final selected poles for the three techniques and the averaged normalized power spectral density. From the aforementioned characteristics, the recommendations given by Wenzel and Pichler (2005), and the authors' experience, the simultaneous use of several methods is a good way to improve the results and to quantify the estimation uncertainties.

Table 1 shows the estimated natural frequencies and damping ratios. A MAC correlation between the modal shapes estimated by three techniques was carried out. Modes that exhibit a MAC value greater than 0.95 for all of the cross values are shown in bold type. Modes with natural frequencies greater than $4 \mathrm{~Hz}(0.8$ times the cutoff frequency of the filter) are not included. Fig. 4 shows an example of identified modal shapes corresponding to the lowest six modes obtained with SSI-cov.

Table 2 shows a summary of the selected modes, including the mean values, the maximum relative error of the natural frequencies, and the maximum absolute error of the damping ratios. It is well known that damping is estimated with greater variability than natural frequencies (Reynders 2012), so it is better to use absolute errors for damping estimates. The maximum errors obtained were $0.6669 \%$ and $26.67 \%$ for frequencies and damping ratios, respectively. It is worth noting the very low values obtained for the
Table 1. Natural Frequencies and Damping Ratios Identified by the Three SSI Techniques

\begin{tabular}{|c|c|c|c|c|c|c|}
\hline \multirow[b]{2}{*}{ Mode } & \multicolumn{2}{|c|}{ SSI-cov } & \multicolumn{2}{|c|}{ SSI-data } & \multicolumn{2}{|c|}{ SSI-EM } \\
\hline & $f(\mathrm{~Hz})$ & $\zeta(\%)$ & $f(\mathrm{~Hz})$ & $\zeta(\%)$ & $f(\mathrm{~Hz})$ & $\zeta(\%)$ \\
\hline 1 & 0.8671 & 0.3352 & 0.8670 & 0.1179 & 0.8671 & 0.1006 \\
\hline & 1.0548 & 0.9622 & 1.0508 & 0.6378 & 1.0526 & 0.6807 \\
\hline 2 & 1.4077 & 0.3792 & 1.4089 & 0.4058 & 1.4135 & 0.6459 \\
\hline 3 & 1.5408 & 0.6762 & 1.5418 & 0.6230 & 1.5511 & 0.7600 \\
\hline 4 & 1.7869 & 0.4483 & 1.7864 & 0.3760 & 1.7884 & 0.1983 \\
\hline 5 & 1.8571 & 0.6381 & 1.8568 & 0.5737 & 1.8590 & 0.3884 \\
\hline & - & - & 2.2977 & 0.3730 & 2.2928 & 0.5868 \\
\hline & 2.3020 & 0.4799 & 2.3041 & 0.4690 & - & - \\
\hline & 2.6819 & 0.3206 & - & - & - & - \\
\hline & - & - & - & - & 2.7838 & 0.6067 \\
\hline & - & - & 2.7949 & 0.4447 & - & - \\
\hline & 2.8051 & 0.5159 & - & - & - & - \\
\hline & - & - & 2.8157 & 0.2338 & 2.8190 & 0.4646 \\
\hline & 2.8682 & 0.3238 & 2.8679 & 0.1601 & - & - \\
\hline & - & - & - & - & 2.8828 & 0.4393 \\
\hline 6 & 3.3674 & 0.4485 & 3.3684 & 0.4092 & 3.3687 & 0.4361 \\
\hline 7 & 3.5375 & 0.8723 & 3.5369 & 0.7968 & 3.5407 & 0.9700 \\
\hline 8 & 3.9487 & 0.5106 & 3.9487 & 0.4873 & 3.9413 & 0.5285 \\
\hline
\end{tabular}

Note: Modes that exhibit a MAC value greater than 0.95 for all of the cross values are shown in bold type. $f=$ natural frequency; $\zeta=$ damping ratio.

damping ratios, although the estimation uncertainty is high, as usual (Moser and Moaveni 2011).

\section{Operational Modal Analysis Using the Same SSI Technique}

To track the modal parameters of a structure, it is recommended to use the minimum test duration that leads to a successful identification. As a rule of thumb, the minimum duration of the measurement should be at least 1,000 cycles of the lowest natural frequency that is expected to be identified (Wenzel and Pichler 2005). This is the minimum duration 


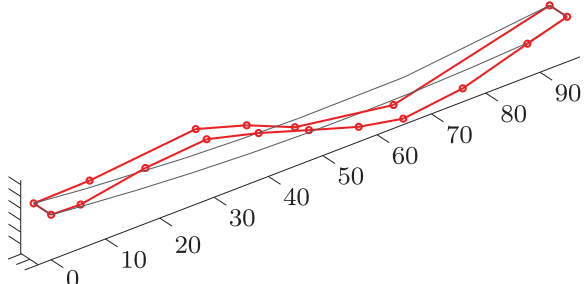

(a)

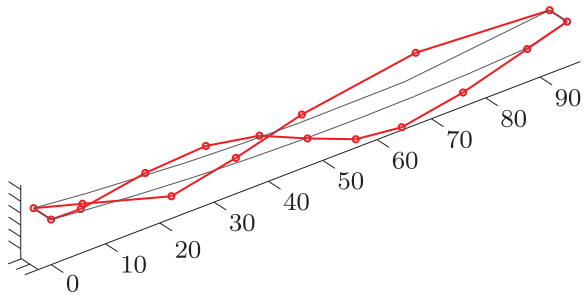

(d)

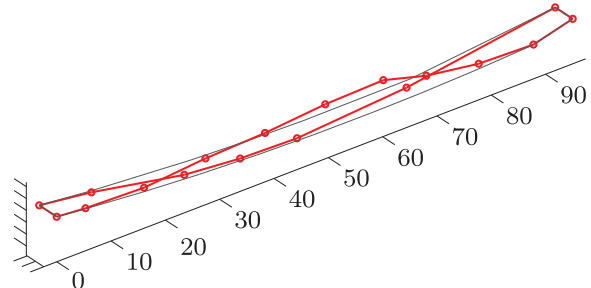

(b)

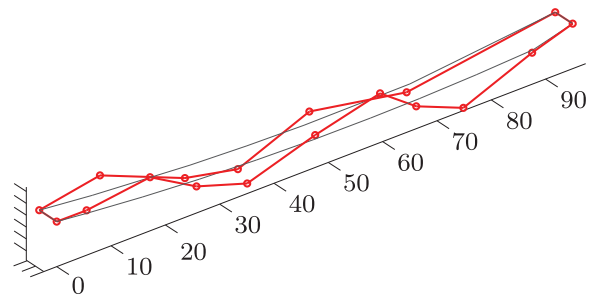

(e)

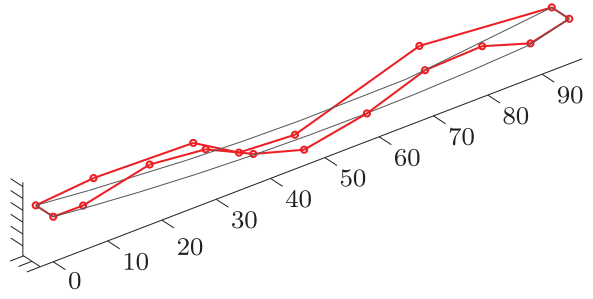

(c)

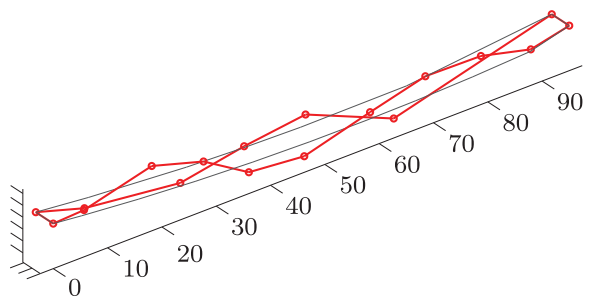

(f)

Fig. 4. First six mode shapes obtained with SSI-cov: (a) $f=0.87 \mathrm{~Hz}$; (b) $f=1.05 \mathrm{~Hz}$; (c) $f=1.41 \mathrm{~Hz}$; (d) $f=1.55 \mathrm{~Hz}$; (e) $f=1.79 \mathrm{~Hz}$; (f) $f=1.86 \mathrm{~Hz}$

Table 2. Summary of Identified Modes and Statistical Comparison for the Three Techniques

\begin{tabular}{lccccc}
\hline & \multicolumn{2}{c}{ Frequency } & & \multicolumn{2}{c}{ Damping } \\
\cline { 2 - 3 } \cline { 5 - 6 } Mode & $\bar{f}(\mathrm{~Hz})$ & Error $(\%)$ & & $\bar{\zeta}(\%)$ & Error $(\%)$ \\
\hline 1 & 0.8671 & 0.0115 & & 0.2346 & 18.46 \\
2 & 1.4100 & 0.4113 & & 0.4770 & $\mathbf{2 6 . 6 7}$ \\
3 & 1.5446 & $\mathbf{0 . 6 6 6 9}$ & & 0.6864 & 13.70 \\
4 & 1.7872 & 0.1119 & & 0.3409 & 25.00 \\
5 & 1.8576 & 0.1184 & & 0.5334 & 24.97 \\
6 & 3.3682 & 0.0386 & & 0.4313 & 3.930 \\
7 & 3.5384 & 0.1074 & & 0.8797 & 17.32 \\
8 & 3.9462 & 0.1875 & & 0.5088 & 4.120 \\
\hline
\end{tabular}

Note: Modes that exhibit a MAC value greater than 0.95 for all of the cross values are shown in bold type. $\bar{f}=$ mean frequency; $\bar{\zeta}=$ mean damping.

usually recommended for noise-contaminated signals and close vibration modes. Therefore, this duration, which corresponds to approximately $20 \mathrm{~min}$, was adopted here to carry out the modal tracking.

Now, three consecutive windows of 20-min data are considered for identifying the modal parameters using only SSI-cov. These results are compared with those obtained by using the 60 -min record. Table 3 shows the estimates obtained from the four data blocks. Using the same criteria as in the previous case, modes that exhibit a MAC value greater than 0.95 for all of the cross values are shown in bold type. The average temperatures for each 20-min time window were $16.42^{\circ} \mathrm{C}, 13.84^{\circ} \mathrm{C}$, and $11.56^{\circ} \mathrm{C}$, respectively, and $13.94^{\circ} \mathrm{C}$ for the 60 -min record.

Table 4 presents a summary of the selected modes, including the mean values for the 20-min tests and the maximum errors compared with the results obtained with the 60-min test. In this case, the maximum errors obtained were $0.2855 \%$ and $61.09 \%$ for frequencies and damping ratios, respectively. The errors in natural frequency estimates using $20 \mathrm{~min}$ compared with that using $60 \mathrm{~min}$ are negligible.

\section{Continuous Dynamic Analysis}

The procedure carried out to track the vibration modes is depicted in Fig. 5. The results obtained from 1 year of continuous dynamic
Table 3. Natural Frequencies and Damping Ratios Identified by SSI-cov and Different Time Blocks

\begin{tabular}{|c|c|c|c|c|c|c|c|c|}
\hline \multirow[b]{2}{*}{ Mode } & \multicolumn{2}{|c|}{$60 \mathrm{~min}$} & \multicolumn{2}{|c|}{ First $20 \mathrm{~min}$} & \multicolumn{2}{|c|}{ Second $20 \mathrm{~min}$} & \multicolumn{2}{|c|}{ Third $20 \mathrm{~min}$} \\
\hline & $f(\mathrm{~Hz})$ & $\zeta(\%)$ & $f(\mathrm{~Hz})$ & $\zeta(\%)$ & $f(\mathrm{~Hz})$ & $\zeta(\%)$ & $f(\mathrm{~Hz})$ & $\zeta(\%)$ \\
\hline - & 0.8671 & 0.3352 & 0.8663 & 0.2526 & - & - & 0.8660 & 1.0824 \\
\hline - & - & - & 1.0251 & 0.3793 & 1.0243 & 0.1433 & 1.0281 & 1.8147 \\
\hline 1 & 1.0548 & 0.9622 & 1.0536 & 0.3755 & 1.0518 & 0.3513 & 1.0535 & 0.4883 \\
\hline 2 & 1.4077 & 0.3792 & 1.4073 & 0.3523 & 1.4059 & 0.5874 & 1.4093 & 0.2594 \\
\hline 3 & 1.5408 & 0.6762 & 1.5408 & 0.5343 & 1.5395 & 0.7945 & 1.5431 & 0.7658 \\
\hline 4 & 1.7869 & 0.4483 & 1.7884 & 0.5036 & 1.7882 & 0.6227 & 1.7833 & 0.4014 \\
\hline 5 & 1.8571 & 0.6381 & 1.8567 & 0.6340 & 1.8574 & 0.6775 & 1.8569 & 0.4995 \\
\hline - & - & - & 1.9260 & 0.3870 & - & - & - & - \\
\hline 6 & 2.3020 & 0.4799 & 2.3022 & 0.4444 & 2.3020 & 0.5353 & 2.3014 & 0.4788 \\
\hline - & 2.6819 & 0.3206 & - & - & 2.6802 & 0.2709 & 2.6836 & 0.2546 \\
\hline - & - & - & - & - & - & - & 2.7306 & 0.4594 \\
\hline - & - & - & - & - & 2.7848 & 0.3825 & - & - \\
\hline - & 2.8051 & 0.5159 & 2.8097 & 0.7520 & - & - & 2.8041 & 0.4918 \\
\hline - & - & - & - & - & 2.8147 & 0.1976 & - & - \\
\hline - & 2.8682 & 0.3238 & - & - & - & - & 2.8631 & 0.3248 \\
\hline - & - & - & 2.9171 & 0.2887 & - & - & - & - \\
\hline 7 & 3.3674 & 0.4485 & 3.3680 & 0.4194 & 3.3659 & 0.4449 & 3.3709 & 0.4587 \\
\hline 8 & 3.5375 & 0.8723 & 3.5356 & 0.6417 & 3.5361 & 0.9920 & 3.5343 & 0.8376 \\
\hline 9 & 3.9487 & 0.5106 & 3.9443 & 0.4427 & 3.9458 & 0.5759 & 3.9552 & 0.3504 \\
\hline
\end{tabular}

Note: Modes that exhibit a MAC value greater than 0.95 for all of the cross values are shown in bold type. $f=$ natural frequency; $\zeta=$ damping ratio.

monitoring are described from now on. First, a method to track the evolution of the main vibration modes over time is described. Then, the influence of the environmental/operational factors on the modal estimates is studied, and correlation models are derived to remove the influence of these spurious factors.

\section{Tracking of Modal Properties}

From the acquired data, an automated OMA was implemented by using SSI-cov. The procedure carried out to remove the environmental/operational effects is depicted in Fig. 5. The process can be divided into the following steps: 
Table 4. Summary of Identified Mode Frequencies and Statistical Comparison for the 20-min versus 1-h Time Blocks

\begin{tabular}{|c|c|c|c|c|}
\hline \multirow[b]{3}{*}{ Mode } & \multicolumn{4}{|c|}{ 20-min time windows } \\
\hline & \multicolumn{2}{|c|}{ Frequency } & \multicolumn{2}{|c|}{ Damping } \\
\hline & $\bar{f}(\mathrm{~Hz})$ & Error $(\%)$ & $\bar{\zeta}(\%)$ & Error $(\%)$ \\
\hline 1 & 1.0530 & 0.2849 & 0.4050 & 61.09 \\
\hline 2 & 1.4075 & 0.2416 & 0.3997 & 32.80 \\
\hline 3 & 1.5411 & 0.2336 & 0.6982 & 26.02 \\
\hline 4 & 1.7866 & 0.2855 & 0.5092 & 22.13 \\
\hline 5 & 1.8570 & 0.0377 & 0.6037 & 17.80 \\
\hline 6 & 2.3019 & 0.0348 & 0.4862 & 9.090 \\
\hline 7 & 3.3683 & 0.1484 & 0.4410 & 3.930 \\
\hline 8 & 3.5353 & 0.0905 & 0.8238 & 35.05 \\
\hline 9 & 3.9484 & 0.2761 & 0.4563 & 22.55 \\
\hline
\end{tabular}

Note: Modes that exhibit a MAC value greater than 0.95 for all of the cross values are shown in bold type. $\bar{f}=$ mean frequency; $\bar{\zeta}=$ mean damping.
- Take the last $N$ tests ( $N$ is the number of tests). $N$ should be representative of the variability of the modal estimates.

- For each test, the OMA is carried out. Thus, a number of modes for each test is identified and denoted as $r_{i}$ (with $i=1 \ldots N)$.

- The objective is to find modal estimates that correspond to the same persistent mode over time. Each modal shape estimate is compared with all the remaining estimates within the $N$ tests, and a counter increases each time that two mode shapes match. The counter indicates the repeatability of a vibration mode. This process is used for all modal shape estimates. To carry out this step, the MAC value is used. That is, a number of

$$
\left[\sum_{i=1}^{N} r_{i}\right]
$$

estimates are compared by using the MAC value. The following three tolerances were defined for this purpose:

- $t_{0} l_{1}$ is a MAC value that enables group estimates corresponding to the same vibration mode. The repeatability is the number of estimates of a group.

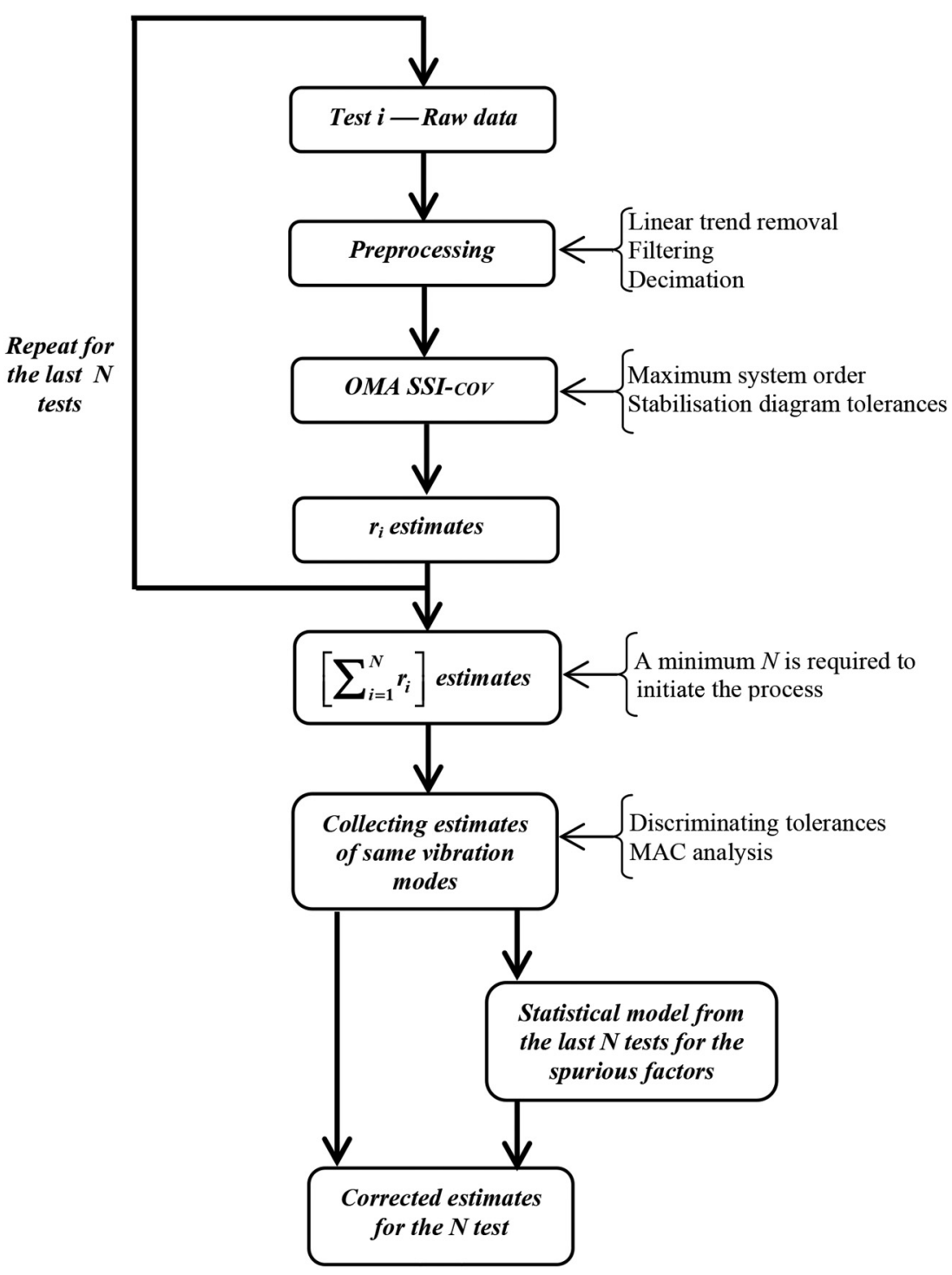

Fig. 5. Tracking procedure for modal parameters 
- $\mathrm{tol}_{2}$ is included to reject groups that are not repeated sufficiently to be considered significant modes. This tolerance is the lower limit of the success ratio (i.e., groups with low repeatability are automatically rejected).

- $\mathrm{tol}_{3}$ is a MAC value included to detect groups of estimates that are actually estimations of the same mode. Then, if more than one group corresponds to the estimation of the same mode, the one with higher repeatability is selected.

- From this procedure, the most significant modes of the dynamic response of the structure are detected for the $N$ tests.

- Variations of these selected modes are statistically studied, and corrected modal parameters are derived.

This tracking method is applied to consecutive time-history records every $20 \mathrm{~min}$ using SSI-cov. During the year 2013, 21,643 tests were taken. The tolerances chosen to carry out the tracking were $t_{0} l_{1} \geq 0.95, t_{0} l_{2} \geq 40 \%$, and $t_{0} \leq 0.80$. Up to nine vibration modes below $4 \mathrm{~Hz}$ were tracked. Table 5 shows statistics of the estimation (mean, standard deviation, absolute percentage variation, and their repeatability; success ratios are included in parentheses). Note that the fourth mode at $1.79 \mathrm{~Hz}$ (with a damping ratio of only $0.42 \%$ ) corresponds to the highest success ratio.

It can be seen that the repeatability of modes is much lower than the total number of tests, which is because some of them are performed under very low-vibration conditions, which leads to wrong estimates that, obviously, are not tracked by the method. The pedestrian traffic over the structure during the daytime hours induces the necessary operational energy that allows successful identification. However, the lack of this excitation during the night hides the real structural response inside the signal noise. Fig. 6 shows hourly distribution of successful identifications obtained for the fourth mode selected (see Table 5).

The time variations of the natural frequency estimates over a year for the lowest ninth mode are shown in Fig. 7(a). Fig. 7(b) presents a magnification showing that the tracking method can identify two closely spaced natural frequencies. Although the monitoring has been operating since January 1, 2013, up to now, some occasional stops (due to minor technical problems and maintenance) tasks can be seen in the figure.

\section{Effects of External Factors}

Strong seasonal and daily trends with temperature have been identified. Fig. 8 shows the time evolution of the frequency estimates of the fourth mode (in the left axis) and temperature (in the right axis).

Table 5. Summary of Identified Natural Frequencies and Damping Ratios for 1-Year Monitoring and Their Statistics

\begin{tabular}{|c|c|c|c|c|c|c|c|}
\hline \multirow[b]{2}{*}{ Mode } & \multicolumn{3}{|c|}{ Frequency } & \multicolumn{3}{|c|}{ Damping } & \multirow{2}{*}{$\begin{array}{l}\text { Repeatability } \\
\text { [number (\%)] }\end{array}$} \\
\hline & $\bar{f}(\mathrm{~Hz})$ & SD & $\nu(\%)$ & $\bar{\zeta}(\%)$ & SD & $\nu(\%)$ & \\
\hline 1 & & 0.0152 & & 0.3665 & 0.1710 & & \\
\hline 2 & 145 & 0.01 & & 31 & 0.15 & 74 & $9.1)$ \\
\hline 3 & 440 & 0.0181 & 27.63 & 0.6498 & 0.2357 & 133. & 5.7) \\
\hline 4 & 1.7937 & 0.0291 & 20.27 & 0.4192 & 0.1502 & & 13, \\
\hline p & 1.8594 & 0.0168 & & .5718 & 0.1605 & 234.74 & 5.9) \\
\hline 6 & 2.3117 & 0.0425 & 15.01 & & 0.1474 & & 10.4) \\
\hline f & 821 & 0.05 & 42.95 & 0.3868 & 0.11 & & $12,210(56.4)$ \\
\hline 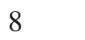 & 3.5512 & 0.0524 & 51.87 & 0.7226 & 0.1884 & 157.48 & $9,237(42.7)$ \\
\hline & 3.9610 & 0.0624 & 8.95 & 0.3853 & 0.1185 & 230.82 & $10,183(57.8)$ \\
\hline
\end{tabular}

Note: Modes that exhibit a MAC value greater than 0.95 for all of the cross values are shown in bold type. $\bar{f}=$ mean frequency; $\mathrm{SD}=$ standard deviation; $\bar{\zeta}=$ mean damping; $\nu=$ corresponding variation.
The seasonal [Fig. 8(a)] and daily [Fig. 8(b)] trends can be seen clearly. Fig. 9 shows the frequency estimates versus temperature for Mode 1 [Fig. 9(a)] and Mode 4 [Fig. 9(b)] of Table 5. It should be noted that the pure vertical response and the thermal behavior (Cacho-Perez et al. 2014) are similar to those of an equivalent suspended cable. Therefore, for these modes (such as Mode 4), increasing temperatures lead to an increase into the ribbon sag, which produces a reduction of band tension and leads to a decrease in the natural frequencies (del Arco et al. 2001). However, Mode 1 [of Table 5 and Fig. 4(b)] does not follow this pattern, because it is a torsional mode.

No other visual evidence of the correlation between the frequency estimates and other factors, different from the temperature, has been found (with neither the wind velocity nor the operational values). Regarding damping ratios, no clear visual dependencies with any external factor have been found.

\section{Statistical Analysis}

A correlation analysis was carried out to study the influence of the external effects on the natural frequencies and damping ratios. The technique used to study the dependence of a dependent variable, $y$, with other independent variables or predictors was multiple linear regression (MLR). The equation of MLR can be written as

$$
y=\mathbf{Z} \boldsymbol{\beta}+\varepsilon=\hat{y}+\varepsilon
$$

where $\mathbf{Z}=\left[1, Z_{1}, \ldots, Z_{k}\right]=$ row vector of $(k+1)$ terms that contain the $k$ predictors; $\boldsymbol{\beta}=\left[\beta_{0}, \beta_{1}, \ldots, \beta_{k}\right]^{\prime}=$ column vector of $(k+1)$ coefficients to be determined that weight the contribution of each predictor; and $\varepsilon=$ residual error. The variable $\hat{y}=\mathbf{Z} \boldsymbol{\beta}$ is the estimate of the statistical model for the dependent variable $y$.

It is important to have an indicator to provide information on the goodness of the regression fitting. The most common indicator is the adjusted coefficient of determination, or adjusted $R^{2}$, because it takes into account the number of observations and predictors included in the model (Cohen et al. 2013). This coefficient represents the proportion of variation of the dependent variable explained by the regression model. The increase in the adjusted $R^{2}$

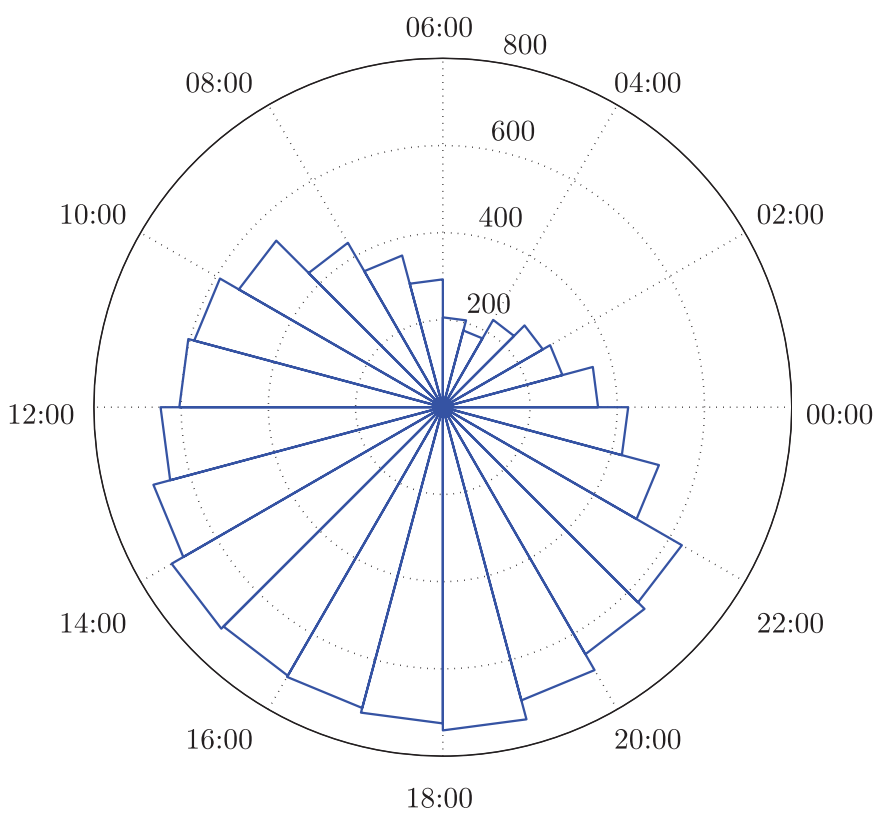

Fig. 6. Distribution per hour of the repeatability for Mode 4 


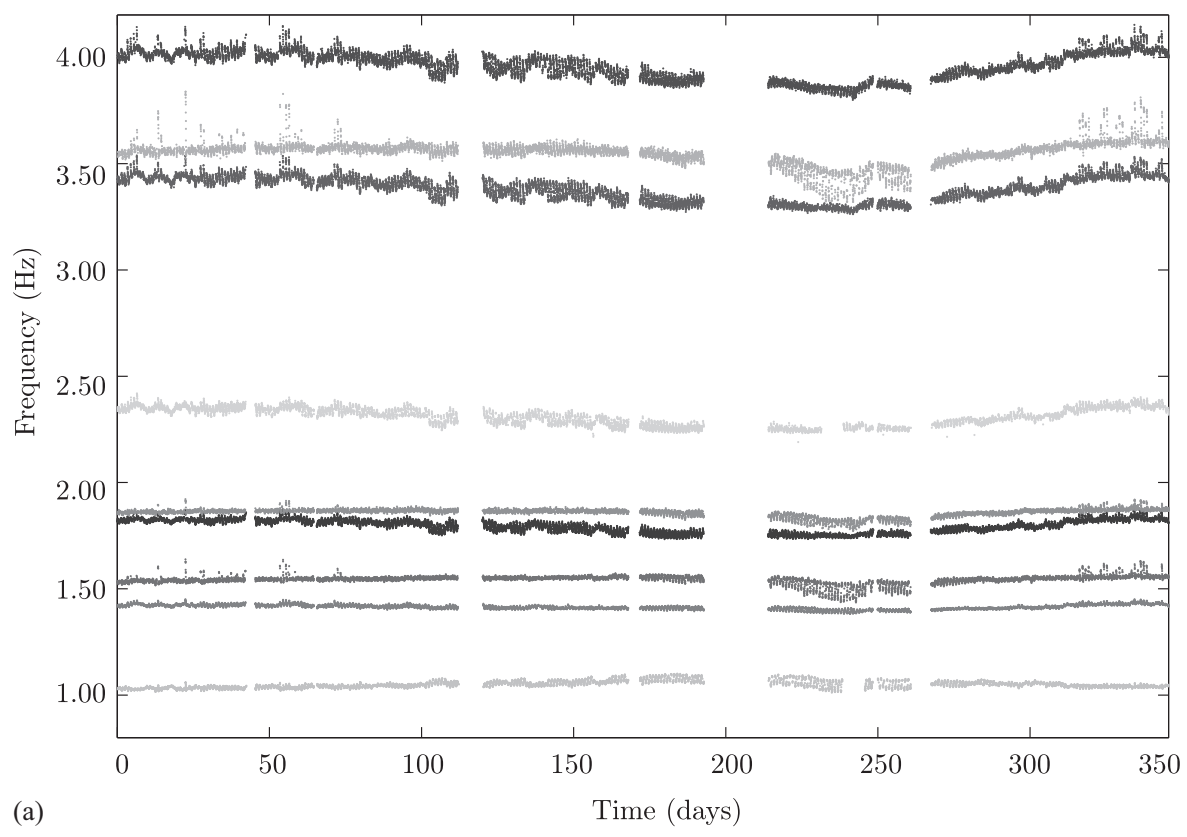

(a)

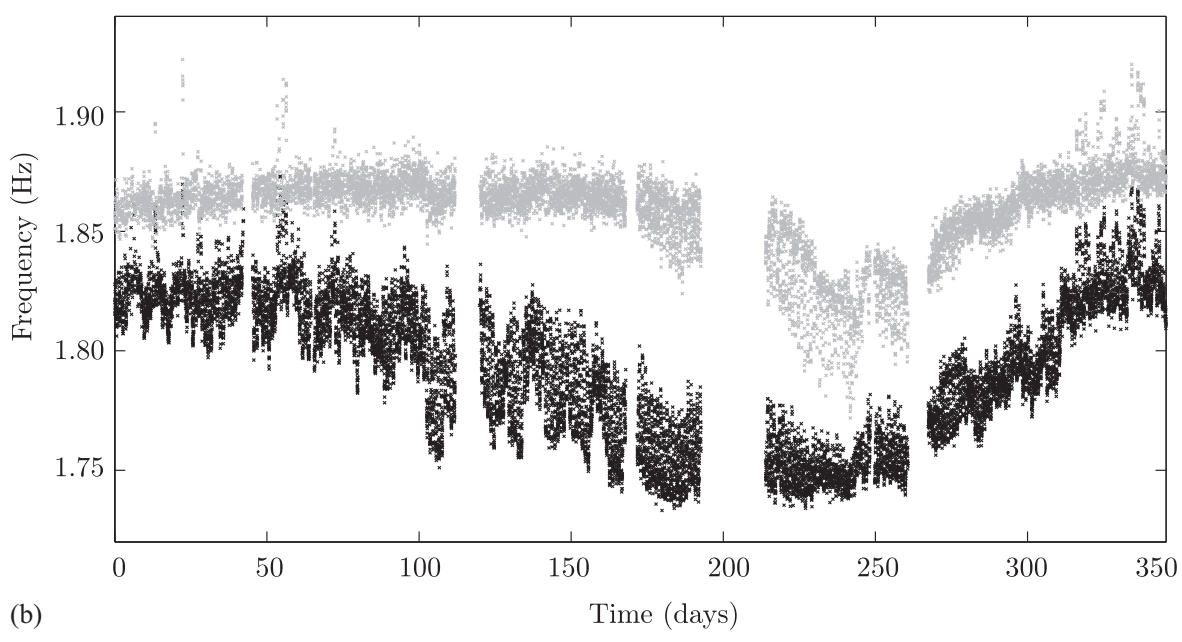

Fig. 7. Tracked frequency estimates for the whole year: (a) complete view; (b) magnified view of the fourth and fifth vibration modes

value by each additional predictor indicates the ratio provided by this predictor.

The independent variables were considered as a function of the ambient temperature, structure acceleration, and wind speed. Thus, the statistical model adopted consists of linearly fitting the independent variables (that might be nonlinear functions of environmental/operational measurements), which are selected according to their statistical relevance. Furthermore, temperature dependence was also explored, not only for this test but also for the temperatures observed in previous tests. That is, a dynamic regression model regarding temperature dependence was adopted.

The estimates were considered as a function of the following variables:

$$
\hat{y}=g\left[T,(\Delta T / \Delta t)_{i}, T_{R_{j}}, a_{\max }, a_{\mathrm{rms}}, V D V, V_{\max }, V_{\mathrm{rms}}\right]
$$

where $\hat{y}=$ modal estimate; $T=$ temperature associated with each test (the mean temperature of the test is taken); $(\Delta T / \Delta t)_{i}=$ gradient of temperature between the current test and the $i$-times former test; $T_{R_{j}}=$ running average temperature using the $j$ previous tests; $a=$ vertical acceleration; and $V=$ wind velocity. The subscripts max and $\mathrm{rms}$ indicate the maximum value and root-mean square, respectively. Thus, $a_{\max }=$ peak acceleration. The variables $a_{\mathrm{rms}}$ (rms acceleration) and VDV (vibration dose value) are integrals of the second and the fourth powers of vertical acceleration, respectively. These are measures suitable for assessing the vibration serviceability for pedestrian structures (ISO 10137 2007). Contrary to peak and rms accelerations, VDV accumulates the vibration effects rather than averaging them and increases with duration. according to Eq. (1), Eq. (2) is considered

$$
\hat{y}=\beta_{0}+\sum_{r=1}^{k} \beta_{r} Z_{r}
$$

in which $Z_{r} \in\left[z_{r}, z_{r}^{2}, \ldots, z_{r}^{n}, 1 / z_{r}, 1 / z_{r}^{2}, \ldots, 1 / z_{r}^{n}\right]$, which thus explores nonlinear relationships, and the $z_{r}$ values are the independent variables that appear in Eq. (2); the coefficients $\beta_{r}$ are obtained from the linear least square solutions; and $k$ is the number of predictors for the model.

To extract the corrected estimates and remove the spurious effects, Eq. (3) is rewritten as follows: 

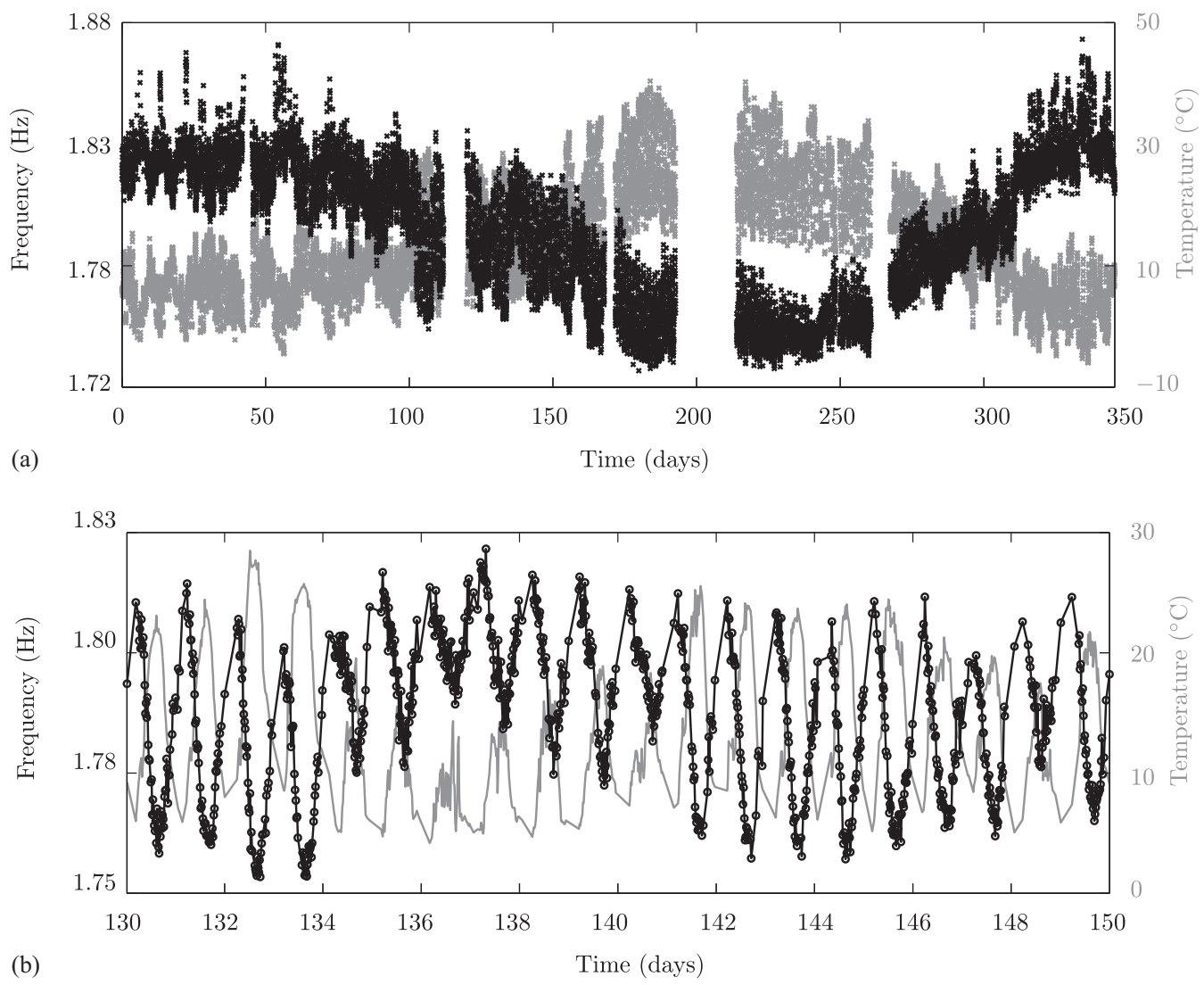

Fig. 8. Frequency estimates and temperature recorded for Mode 4: (a) complete view; (b) magnified view of 20 days

$$
\hat{y}=\underbrace{\left(\beta_{0}+\sum_{r=1}^{k} \beta_{r} \overline{Z_{r}}\right)}_{y^{*}}+\sum_{r=1}^{k} \beta_{r}\left(Z_{r}-\overline{Z_{r}}\right)
$$

where $\overline{Z_{r}}=$ mean value of all the observations of $Z_{r}$; and $y^{*}=$ corrected estimate, defined as

$$
y^{*}=\beta_{0}+\sum_{r=1}^{k} \beta_{r} \overline{Z_{r}}
$$

The MLR method presented here was applied to frequency and damping ratio estimates for all of the tracked modes (of Table 5). It was considered that $i=1,2, \ldots, 30, j=50,100,250,1,000$, 1,500, and 2,000 [see Eq. (2)], and $n=3$ and $k=4$ [see Eq. (3) and definition of $Z_{r}$ ]. Eventually, 252 candidates for predictors were considered. Thus, Table 6 shows the values of the adjusted $R^{2}$ values for all the natural frequency estimates of the selected modes as the number of predictors increased in the statistical models. The predictors of those models that obtained a value of the adjusted $R^{2}$ greater than 0.80 are also shown in Table 6 . The last column of the table shows the maximum adjusted $R^{2}$ and $R_{\max }^{2}$ values obtained for the maximum number of predictors and the $k_{\max }$ value for each model (shown in parentheses). It can be seen that those modes with a higher adjusted $R^{2}$ (Modes 4, 6, 7, and 9), $R_{\max }^{2}>0.90$, have as predictors independent variables related to the temperature. It can also be seen that there are two modes, 1 and 2, with adjusted $R^{2}$ values close to 0.80 , for which serviceability parameters were used as the third and fourth predictors for their respective models (see Table 6).
The frequency distribution for each mode is shown in Fig. 10. There are some modes $(3,5$, and 8$)$ with a frequency that have a very narrow distribution, indicating that (1) they do not change significantly, (2) they do not need any correction, and (3) they might already be used for SHM. Therefore, the variation of these modes cannot be explained, which leads to adjusted $R^{2}$ values lower than the remainders.

Finally, very low values for the adjusted $R^{2}$ value (smaller than $0.20)$ were achieved for damping ratios. Therefore, the results for the damping ratios are not presented here, because there is no clear dependency of damping ratio variations.

\section{Removing External Factors}

As an example, the model obtained for the natural frequency estimate of Mode 4 is expounded in detail. This is the mode with the highest success ratio, and its model achieves the highest adjusted $R^{2}$ value. The model obtained for the statistical frequency is as follows:

$$
\hat{f}=\beta_{0}+\underbrace{\beta_{1} \cdot T+\beta_{2} \cdot(\Delta T / \Delta t)_{19}+\beta_{4} \cdot T^{2}}_{\text {daily }}+\underbrace{\beta_{3} \cdot T_{R_{1,000}}}_{\text {seasonal }}
$$

where $\hat{f}=$ frequency estimate by statistical model. Eq. (6) shows the dependency on temperature and on the temperature gradient with respect to the 19-times former test $\left(\Delta t_{19}=19 \cdot 20=380 \mathrm{~min}\right)$; the running average temperature used 1,000 previous tests and temperature to the second power. These values provided the higher increment of the adjusted $R^{2}$. Additional predictors introduced only marginal improvements to the correlation. 
To test this statistical model, data from the first 20 days of January 2014 were used as unseen data. Fig. 11 shows the frequency estimates according to the SSI-cov technique and the statistical model [Eq. (6)]. The maximum relative error did not exceeded $1 \%$.

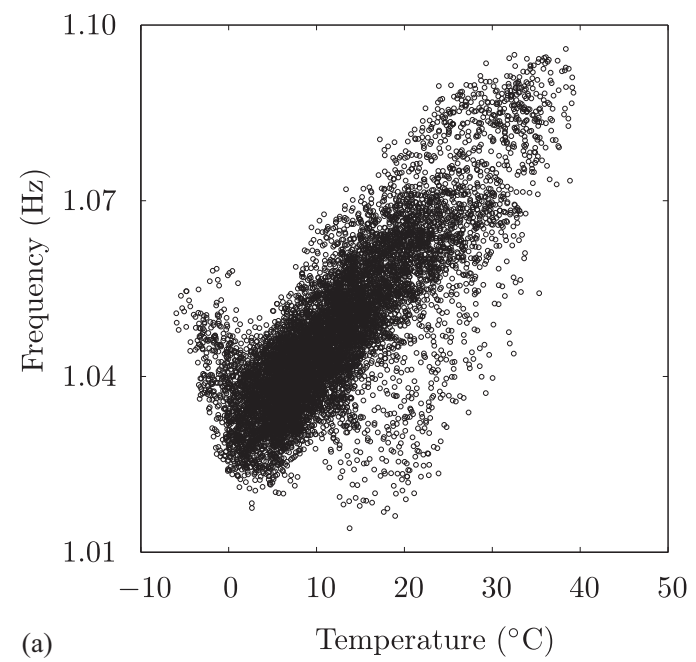

(a)

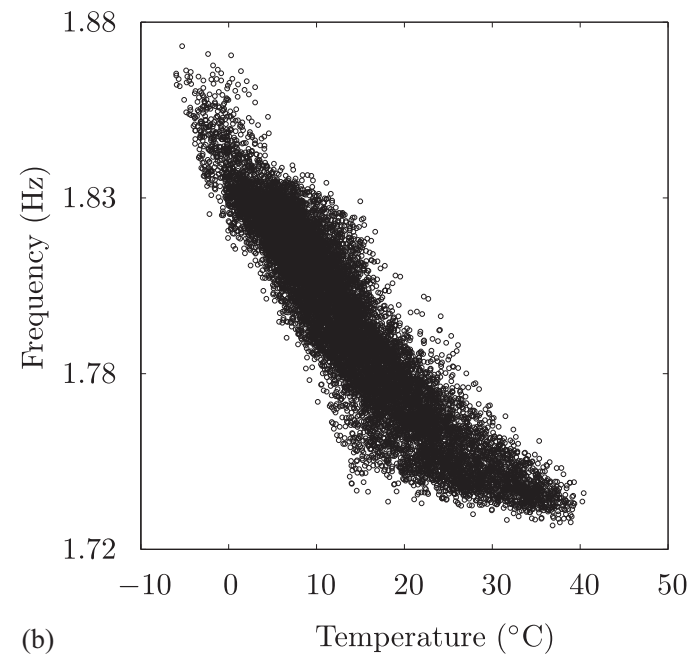

Fig. 9. Frequency estimates versus temperature for (a) Mode 1 and (b) Mode 4

Table 6. Adjusted $R^{2}$ and Independent Variable for Each Statistical Model According to the Number of Predictors

\begin{tabular}{|c|c|c|c|c|c|c|c|c|c|}
\hline \multirow[b]{3}{*}{ Mode } & \multicolumn{9}{|c|}{ Predictors, $k$} \\
\hline & \multicolumn{2}{|c|}{1} & \multicolumn{2}{|c|}{2} & \multicolumn{2}{|c|}{3} & \multicolumn{2}{|c|}{4} & \multirow[b]{2}{*}{$R_{\text {max }}^{2}\left(k_{\max }\right)$} \\
\hline & Number & Variable & Number & Variable & Number & Variable & Number & Variable & \\
\hline 1 & 0.627 & $T$ & 0.761 & $(\Delta T / \Delta t)_{9}$ & 0.777 & $1 / a_{\mathrm{rms}}$ & 0.785 & $T^{2}$ & $0.839(52)$ \\
\hline 2 & 0.616 & $T_{R_{1,000}}$ & 0.651 & $T$ & 0.782 & $T^{2}$ & 0.791 & $1 / a_{\mathrm{rms}}$ & $0.841(45)$ \\
\hline 3 & 0.157 & & 0.222 & & 0.268 & & 0.325 & & $0.440(35)$ \\
\hline 4 & 0.850 & $T$ & 0.921 & $(\Delta T / \Delta t)_{19}$ & 0.942 & $T_{R_{1,000}}$ & 0.955 & $T^{2}$ & $0.967(36)$ \\
\hline 5 & 0.521 & & 0.537 & & 0.553 & & 0.565 & & $0.621(34)$ \\
\hline 6 & 0.874 & $T$ & 0.929 & $(\Delta T / \Delta t)_{18}$ & 0.943 & $T_{R_{1,000}}$ & 0.951 & $T^{2}$ & $0.964(56)$ \\
\hline 7 & 0.826 & $T$ & 0.905 & $T_{R_{1,000}}$ & 0.925 & $(\Delta T / \Delta t)_{11}$ & 0.943 & $T^{2}$ & $0.953(38)$ \\
\hline 8 & 0.502 & & 0.546 & & 0.567 & & 0.577 & & $0.653(41)$ \\
\hline 9 & 0.799 & $T_{R_{1,000}}$ & 0.886 & $T$ & 0.907 & $T^{2}$ & 0.918 & $(\Delta T / \Delta t)_{10}$ & $0.929(29)$ \\
\hline
\end{tabular}

Note: Modes that exhibit a MAC value greater than 0.95 for all of the cross values are shown in bold type. 


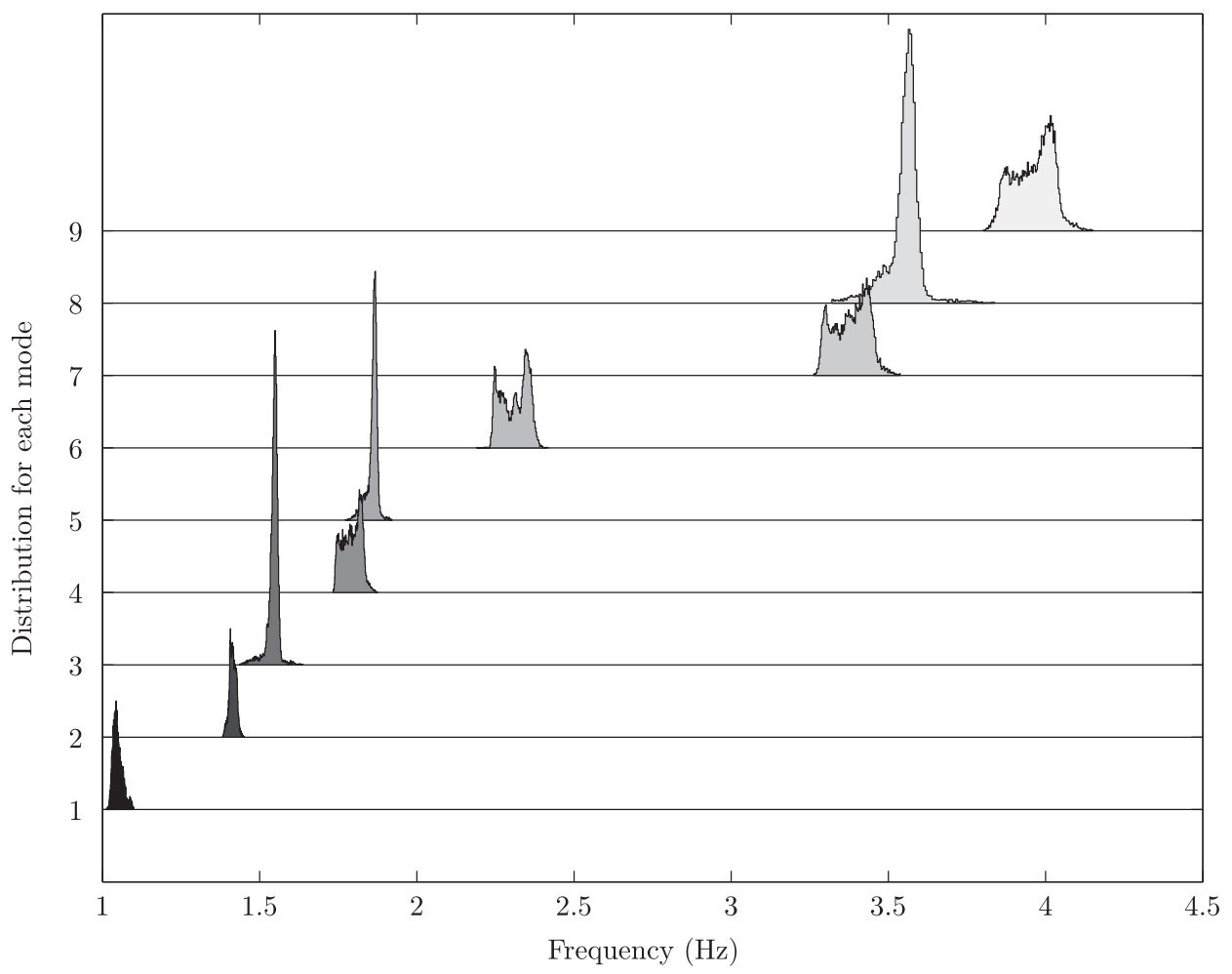

Fig. 10. Overlaid distributions of the identified natural frequencies

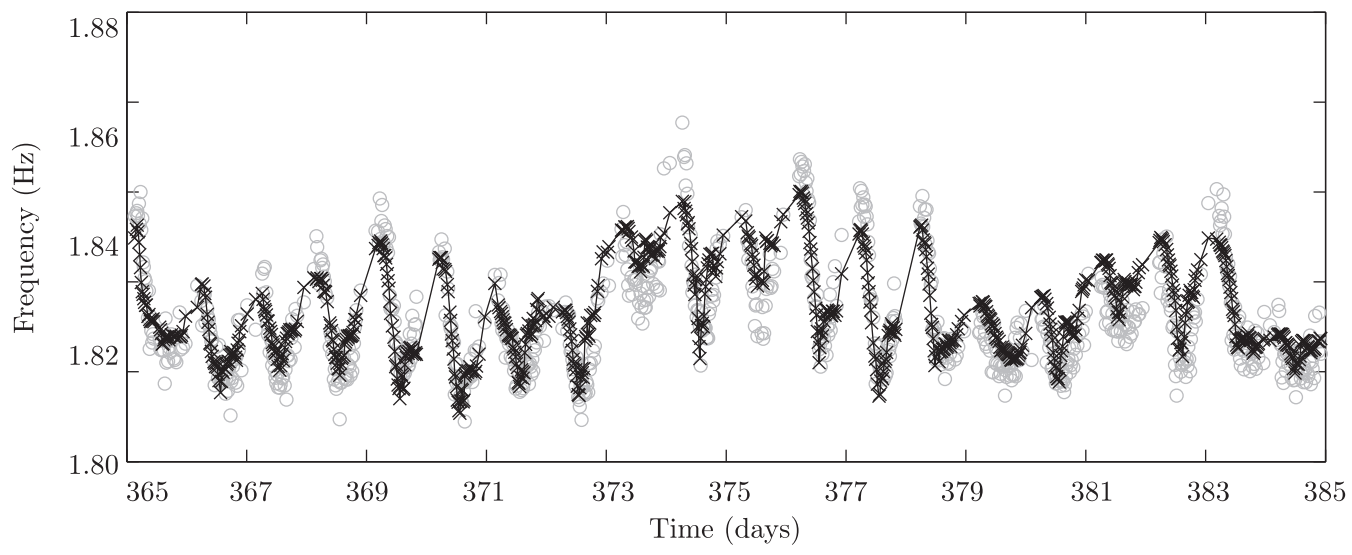

Fig. 11. Validation of the statistical model with "unseen data"; circles indicate SSI estimates, and crosses indicate estimates from the statistical model

footbridge, and it is currently providing live data for its analysis. It has been demonstrated that these low-cost sensors, carefully conditioned, can be a competitive alternative to the traditional ones. Thus, using this innovate system, this study has focused mainly on the time evolution of the modal parameters and their correlation against environmental/operational factors. A simple and efficient method of removing environmental effects was carried out on the basis of dynamic linearized multiple regression. A correction of these modal parameters was proposed in such a way that the corrected frequencies might be used as a potential damage index in a SHM system. It should be noted that the presented methodology for tracking the modal parameters and removing the influence of external factors can be applied to other bridges following the same steps while considering that the predictors may be different.

It was demonstrated that this particular stress-ribbon structure is highly sensitive to temperature variations (frequency changes of more than 20\%). Although only one ambient temperature sensor was installed, an interesting statistical model for the frequency estimates was derived. This model makes use of not only the temperature but also the gradient of temperature and the running averaged temperature, which explain more than $95 \%$ of the frequency variations over time for two of the vibration modes. A procedure for obtaining the corrected frequency (removing the influence of external factors) has been proposed, and the residual error in this case was shown to be fitted to a narrow normal Gaussian distribution. This feature makes 

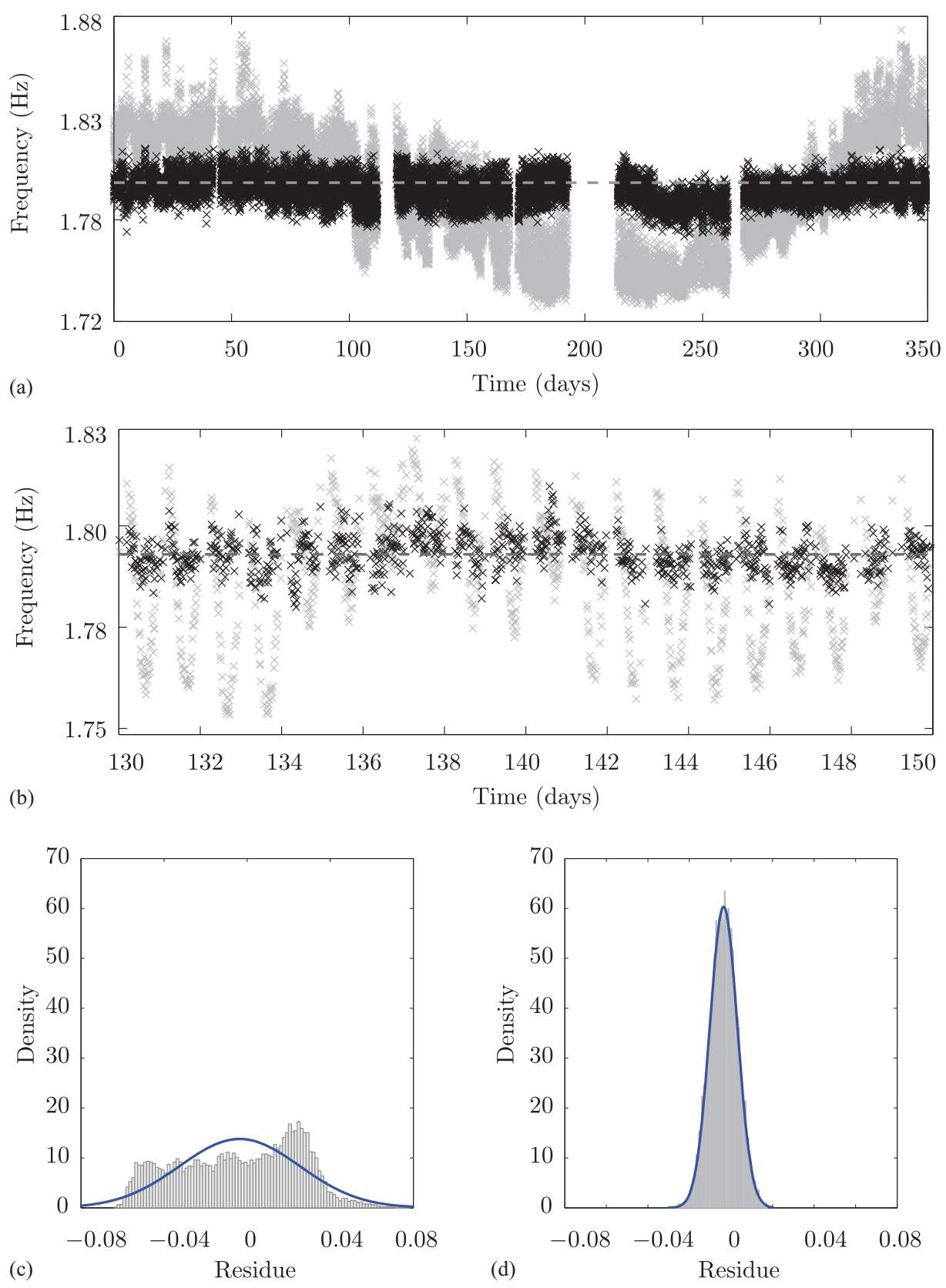

Fig. 12. Removing the external factors for Mode 4: (a) complete view; (b) magnified view of 20 days; (c) residue before correcting; (d) residue after correcting; grey crosses indicate SSI estimates $f^{(\mathrm{SSI})}$; black crosses indicate corrected frequency estimates $\hat{f}^{*}$; and grey dashed lines indicate corrected frequency $f^{*}$

modal estimates more appropriate for use as damage detectors. Furthermore, the uncertainties that result from the estimation process (using different SSI techniques and different data blocks) were studied. The corrected frequency had a closer range of variability than the original one. However, the variability for the corrected frequency had a wider range than the errors quantified from the estimation process.

Future work should consider the development of a finite-element model for this strongly nonlinear structure and its model updating. The results obtained in this paper are essential for the development of a reliable model that might be used with a SHM system. Future work should also consider studying the optimal way to update the statistical models while taking into consideration model accuracy and computational burden, because both of them can be critical for their use in a SHM system.

\section{Acknowledgments}

The authors acknowledge the financial support provided by the Spanish Government Research Program with the Grant BIA201128493 and by the project SETH of INNPACTO Program with reference IPT-2012-0703-380000. The authors also acknowledge the financial support provided by Research Project DPI201347441-P.

\section{References}

Andersen, P. (1997). "Identification of civil engineering structures using vector ARMA models." Ph.D. thesis, Aalborg Univ., Aalborg, Denmark. 
Avci, O. (2014). "Modal parameter variations due to joist bottom chord extension installations on laboratory footbridges." J. Perform. Constr. Facil., 10.1061/(ASCE)CF.1943-5509.0000635, 04014140.

Bauer, D. (2005). "Asymptotic properties of subspace estimators." Automatica, 41(3), 359-376.

Bayraktar, A., Altunişik, A. C., Sevim, B., and Türker, T. (2009). "Modal testing, finite-element model updating, and dynamic analysis of an arch type steel footbridge." J. Perform. Constr. Facil., 10.1061/(ASCE)0887 -3828(2009)23:2(81), 81-89.

Cacho-Perez, M., Frechilla, N., Diaz, I., and Lorenzana, A. (2014). "Simplified mechanical model for a stress-ribbon monitorized footbridge: Analytical and experimental results." Proc., 6th World Conf. on Structural Control and Monitoring, International Center for Numerical Methods in Engineering, Barcelona, Spain, 358-368.

Cara, F. J., Carpio, J., Juan, J., and Alarcón, E. (2012). "An approach to operational modal analysis using the expectation maximization algorithm.” Mech. Syst. Sig. Process., 31, 109-129.

Chiuso, A., and Picci, G. (2004). "The asymptotic variance of subspace estimates." J. Econometrics, 118(1), 257-291.

Cismaşiu, C., Narciso, A. C., and Amarante dos Santos, F. P. P. (2014). "Experimental dynamic characterization and finite-element updating of a footbridge structure." J. Perform. Constr. Facil., 10.1061/(ASCE)CF .1943-5509.0000615, 64014116.

Cohen, J., Cohen, P., West, S. G., and Aiken, L. S. (2013). Applied multiple regression/correlation analysis for the behavioral sciences, Routledge, London.

Costa, B. J. A., Magalhães, F., Cunha, A., and Figueiras, J. (2014). "Modal analysis for the rehabilitation assessment of the Luiz I Bridge." $J$. Bridge Eng., 10.1061/(ASCE)BE.1943-5592.0000632, 05014006.

Cross, E., Koo, K., Brownjohn, J., and Worden, K. (2013). "Long-term monitoring and data analysis of the Tamar Bridge." Mech. Syst. Sig. Process., 35(1-2), 16-34.

de Sebastián, J., Escudero, A., Arnaz, R., Díaz, I., Poncela, A., and Lorenzana, A. (2013). "A low-cost vibration monitoring system for a stress-ribbon footbridge." Proc., 6th ECCOMAS Conf. on Smart Structures and Materials, SMART2013, Trans Tech Publications, Durnten-Zurich, Switzerland.

del Arco, D. C., Aparicio, A., and Marí, A. (2001). "Preliminary design of prestressed concrete stress ribbon bridge." J. Bridge Eng., 10.1061 /(ASCE)1084-0702(2001)6:4(234), 234-242.

Deraemaeker, A., Reynders, E., De Roeck, G., and Kullaa, J. (2008). "Vibration-based structural health monitoring using output-only measurements under changing environment." Mech. Syst. Sig. Process., 22(1), 34-56.

Gomez, H. C., Fanning, P. J., Feng, M. Q., and Lee, S. (2011). “Testing and long-term monitoring of a curved concrete box girder bridge." Eng. Struct., 33(10), 2861-2869.

Hu, W., Caetano, E., and Cuhna, A. (2012). "Structural health monitoring of a stress-ribbon footbridge." Eng. Struct., 47, 578-593.

Hua, X. G., Ni, Y. Q., Ko, J. M., Asce, F., and Wong, K. Y. (2007) "Modeling of temperature-frequency correlation using combined principal component analysis and support." J. Comput. Civil Eng., 10.1061 /(ASCE)0887-3801(2007)21:2(122), 122-135.

ISO. (2007). "Bases for design of structures: Serviceability of buildings and walkways against vibrations," ISO 10137, Geneva.

Ivorra, S., Foti, D., Bru, D., Javier, F. B., and Baeza, F. J. (2013). "Dynamic behavior of a pedestrian bridge in Alicante, Spain." J. Perform. Constr. Facil., 10.1061/(ASCE)CF.1943-5509.0000556.

Jacobsen, N., Andersen, P., and Brincker, R. (2008). "Applications of frequency domain curve-fitting in the EFDD technique." Proc., International Modal Analysis Conf., IMAC 26, Curran, Red Hook, NY.

Koo, K. Y., Brownjohn, J. M. W., List, D. I., and Cole, R. (2013). "Structural health monitoring of the Tamar suspension bridge." Struct. Control Health Monit., 20(4), 609-625.

Liu, C., and DeWolf, J. T. (2007). "Effect of temperature on modal variability of a curved concrete bridge under ambient loads." J. Struct. Eng., 10 1061/(ASCE)0733-9445(2007)133:12(1742), 1742-1751.
López, J. A., and Astiz, M. A. (2014). "An experimental analysis of the evolution of dynamic parameters of a long-span metal arch bridge." Struct. Eng. Int., 24(1), 8-19.

MacLamore, V., Hart, G., and Stubbs, I. (1971). "Ambient vibration of two suspension bridges.” J. Struct. Div., 97(10), 2567-2582.

Magalhães, F., and Cunha, A. (2011). "Explaining operational modal analysis with data from an arch bridge." Mech. Syst. Sig. Process., 25(5), 1431-1450.

Magalhães, F., Cunha, A., and Caetano, E. (2008a). "Dynamic monitoring of a long span arch bridge." Eng. Struct., 30(11), 3034-3044.

Magalhães, F., Cunha, A., and Caetano, E. (2008b). "Permanent monitoring of 'Infante D. Henrique' bridge based on FDD and SSI-COV methods." Proc., Int. Conf. on Noise and Vibration Engineering, P. Sas and B. Bergen, eds., Vol. 1, Katholieke Univ. Leuven, Leuven, Belgium, 649664.

Magalhães, F., Cunha, A., and Caetano, E. (2012). "Vibration based structural health monitoring of an arch bridge: From automated OMA to damage detection." Mech. Syst. Sig. Process., 28, 212-228.

MATLAB 8.3.0.532 (2014). MathWorks, Inc., Natick, MA

McLachlan, G., and Krishnan, T. (2007). The EM algorithm and extensions, John Wiley \& Sons, New York.

Moaveni, B., and Behmanesh, I. (2012). "Effects of changing ambient temperature on finite element model updating of the Dowling Hall Footbridge." Eng. Struct., 43, 58-68.

Mosavi, A. A., Seracino, R., and Rizkalla, S. (2012). "Effect of temperature on daily modal variability of a steel-concrete composite bridge." $J$. Bridge Eng., 10.1061/(ASCE)BE.1943-5592.0000372,979-983.

Moser, P., and Moaveni, B. (2011). "Environmental effects on the identified natural frequencies of the Dowling Hall footbridge." Mech. Syst. Sig. Process., 25(7), 2336-2357.

Moser, P., and Moaveni, B. (2013). "Design and deployment of a continuous monitoring system for the Dowling Hall footbridge." Exp. Tech., $37(1), 15-26$.

Narros, A. (2011). "Pasarela Peatonal 'Pedro Gómez Bosque' sobre el Río Pisuerga en la Ciudad de Valladolid. Un Nuevo Récord de Longitud en Pasarelas Colgadas de Banda Tesa." Rev. Tec. Cemento-Hormigón, 947, 80-86 (in Spanish).

Ni, Y., Hua, X., Fan, K., and Ko, J. (2005). "Correlating modal properties with temperature using long-term monitoring data and support vector machine technique." Eng. Struct., 27(12), 1762-1773.

Overschee, P. V., and Moor, B. D. (1996). Subspace identification for linear systems, Kluwer Academic, Boston.

Peeters, B., and De Roeck, G. (1999). "Reference-based stochastic subspace identification for output-only modal analysis." Mech. Syst. Sig. Process., 13(6), 855-878.

Reynders, E. (2012). "System identification methods for (operational) modal analysis: Review and comparison." Arch. Comput. Methods Eng., 19(1), 51-124.

Reynders, E., Houbrechts, J., and De Roeck, G. (2012). "Fully automated (operational) modal analysis." Mech. Syst. Sig. Process., 29, 228-250.

Reynders, E., Schevenels, M., and Roeck, G. D. (2008). "MACEC: A $M A T L A B$ toolbox for experimental and operational modal analysis." Katholieke Univ. Leuven, Leuven, Belgium.

Stiros, S., and Moschas, F. (2014). "Rapid decay of a timber footbridge and changes in its modal frequencies derived from multiannual lateral deflection measurements." J. Bridge Eng., 10.1061/(ASCE)BE.1943 $-5592.0000629,05014005$.

Wenzel, H., and Pichler, D. (2005). Ambient vibration monitoring, John Wiley \& Sons, West Sussex, U.K.

Zhang, T., Wang, Y., and Tamura, A. (2010). "A frequency-spatial domain decomposition (FSDD) method for operational modal analysis." Mech. Syst. Sig. Process., 24(5), 1227-1239.

Zhou, H. F., Ni, Y. Q., and Ko, J. M. (2011). "Eliminating temperature effect in vibration-based structural damage detection." J. Eng. Mech., 10 .1061/(ASCE)EM.1943-7889.0000273, 785-796. 